\title{
Can microbial activity enhance chromium removal from industrial stormwater?
}

\author{
BRANDY D. STEWART ${ }^{1}$, CODY SHEIK ${ }^{2}$, PAUl EGER ${ }^{3}$,
} BRANDY M. TONER ${ }^{1}$

${ }^{1}$ University of Minnesota-Twin Cities, St. Paul, MN, 55108

(correspondence: stewarb@umn, edu, toner@umn.edu)

${ }^{2}$ University of Minnesota-Duluth (cssheik@d.umn.edu)

${ }^{3}$ Global Minerals, (paul.eger@globalmineralseng.com)

Treatment processes for metals in industrial waste streams can be cost prohibitive; therefore, passive remediation strategies using natural materials and harnessing microbial processes have the potential to provide affordable solutions which is important from regulatory and environmental quality perspectives. Our research explores the key chemical, biological, and physical processes promoting removal of hexavalent chromium ( $\mathrm{Cr}$ ) from an industrial stormwater treatment system by association with granular organic peat media. In this installation chromium is primarily in the water soluble and carcinogenic hexavalent form, chromate. Prior to treatment, chromate is converted to $\mathrm{Cr}(\mathrm{III})$ via an oxidationreduction reaction using iron sulfate. The resulting $\mathrm{Cr}(\mathrm{III})$ is less water soluble than chromate, making $\mathrm{Cr}$ precipitation as hydroxides possible. The removal capacity for $\mathrm{Cr}(\mathrm{III})$ is much higher than expected for adsorption and filtration by the peat media alone, suggesting other mechanisms, including microbially mediated attenuation may play a role. In addition to filtration of $\mathrm{Cr}(\mathrm{III})$ precipitates, the presence of iron (from the pre-treatment step) could yield $\mathrm{Cr}(\mathrm{III})$ co-precipitation with $\mathrm{Fe}$ minerals and/or serve as a terminal electron acceptor.

Samples were collected from the treatment site in Howell, MI USA, where Cr-laden stormwater is treated in large tank reactors filled with peat sorbent material. We sampled one reactor in four different locations at four depths for a total of 16 solid-phase peat material samples. DNA was extracted to collect metagenomic data and microbial coupons were installed in the tanks to harvest biofilm samples. Chemical digestions show total $\mathrm{Cr}$ concentrations ranging from 400$900 \mathrm{mg} / \mathrm{kg}$. X-ray Fluorescence Microprobe (XFM) data reveal that $\mathrm{Cr}$ is heterogeneously distributed within the bioremediation media with diffuse and "hot spot" features on the micron to 10 s of micron scale. Additionally, results show $\mathrm{Cr}(\mathrm{III})$-bearing particles and metallic $\mathrm{Cr}$ bearing particles in the same sample. Lastly, incubations innoculated with microbial cultures, containing $\mathrm{Cr}(\mathrm{VI})$ and peat demonstrate efficient reduction to $\mathrm{Cr}(\mathrm{III})$. 